\title{
EXPERT SYSTEM PORTFOLIOS OF AUSTRALIAN AND UK SECURITISED PROPERTY INVESTMENTS
}

\author{
CRAIG ELLIS \\ University of Western Sydney \\ and \\ PATRICK WILSON \\ University of Technology, Sydney
}

\begin{abstract}
This paper examines whether a rule-based expert system is capable of outperforming the general property market, as well as randomly constructed portfolios from the market. While neural network expert systems have been used in property research, there appears little in the literature on the application of rule-based expert systems. Secondly, the paper considers whether there are benefits to international investment in real estate securities. The perspective of the analysis is that of an Australian investor investing in both the domestic market and the UK property market. Several results ensue including the failure of the rule-based system to significantly outperform the market or the random portfolios on a risk-adjusted returns basis, and the failure of hedging to secure a positive rate of return to the portfolio.
\end{abstract}

Keywords: Expert system, international investment, hedging, portfolios

\section{INTRODUCTION}

One of the roles of the Australian Prudential Regulatory Authority (APRA) is to consider whether Australian financial institutions are obtaining diversification benefits through their international holdings of financial assets including real estate - both direct and indirect. The current paper considers this issue as part of a two-fold purpose as indicated below. This paper is an extension of previous research by the authors into the usefulness of Artificial Intelligence (AI) systems in portfolio construction (Ellis and Wilson, 2005). While that paper analysed the outcomes from neural network based systems in asset selection, this paper seeks to: (i) develop a rule-based expert system that can be used for selecting 'value' property stocks from the set of Australian and UK property stocks, and assess the ability of such a portfolio to outperform the general securitised property market in Australia; and (ii) to assess the viability of an Australian property investor receiving positive returns from either hedged or unhedged positions if investing in the 
UK securitized property market.

Why this may be important follows directly from other research that has questioned the viability of benefits arising from international diversification in real estate investment (eg: Ziobrowski and Ziobrowski (1993), Wilson and Zurbruegg (2003, 2004)) and the findings may be of some interest to both APRA as well as to property portfolio managers within Australian financial institutions. Several results follow from the paper's analysis. While the rule-based expert system 'value' portfolios of Australian stocks are shown to outperform a randomly selected portfolio in most cases, they fail to outperform the Australian property market. Interestingly, the expert system 'value' portfolios selected from UK property stocks outperform both the Australian property market and the randomly selected portfolio in most instances. A central outcome is that none of these results are statistically significant and attempts to hedge AUD/GBP exchange rate movements result in capital losses to all portfolios, leading us to question the sustainability of long-term hedging in securitised property markets.

\section{BRIEF OVERVIEW OF EXPERT SYSTEMS}

One definition of a rule-based expert system is a computer programme that is capable of using information contained in a knowledge base, along with a set of inference procedures, to solve problems that are difficult enough to require significant human expertise for their solution (Harmon and King, 1985). The set of inference procedures are provided by a human expert in the particular area of interest, while the knowledge base is an accumulation of relevant data, facts, judgments and outcomes.

There have been several studies on the use of different types of expert system in business. Wilson (1987) presents a number of applications of expert systems in finance, investment, taxation, accounting and administration, but points to the restrictions on the broader development of expert systems in business posed by the hardware limitations of the time. In their survey articles on the use of expert systems in business from 1977 through 1993, Wong and Monaco (1995a,b) note that expert systems have evolved and have been implemented as practical decision making tools in many businesses, documenting an extensive use of expert systems in various areas of finance such as investment analysis, stock market trading and financial planning. Despite this finding, Ellis Johnson et al (1997) find very little evidence of the application of formal decision support systems, such as expert systems, in the real estate sector.

Liao (2005) conducts a review of the use of expert systems across all areas, including finance, over the period 1995 through 2004 and observes that expert systems provide a powerful and flexible means of obtaining solutions to a variety of problems and can be called upon as needed (when a human with expertise in the particular area may not be available). Of the different categories of expert systems as classified by Liao, there has been a broad examination of Neural Network (NN) based expert systems in property 
research. For instance Borst (1991) examines the usefulness of NNs in predicting the selling price of real estate. Tay and Ho (1991), Do and Grudnitski (1992), Worzala et al (1995) and McGreal et al (1998) all examine the effectiveness of NN systems in property appraisal. Nguyen and Cripps (2001) compare the predictive accuracy of NNs against regression in forecasting housing values, and Wilson et al (2002) use NNs to forecast future trends within the UK housing market. Brooks and Tsolacos (2003) suggest that analysts should exploit the potential of NNs and assess more fully their forecast performance against more traditional models, and more recently, Ellis and Wilson (2005) examine the applicability of a neural network expert system in the construction of portfolios of Australian securitised property. It would appear that there has been little in the way of examination of the usefulness and applicability of rule-based expert systems in property market research.

\section{DATA AND SAMPLE}

The data utilised in this study comprises nominal monthly values for real estate stocks listed on the Australian Stock Exchange (ASX) and the London Stock Exchange (LSE) from January 1996 to February 2004 inclusive, a total of 98 months. The stocks selected are those listed in the Datastream Australian Real Estate Index and the Datastream UK Real Estate Index ${ }^{1}$. The Datastream Australian Real Estate Index comprises the top 80\% of property sector stocks in the Australian market. Stocks included in the Index own property and derive their income from rental returns. As at February 2004, the Datastream Australian Real Estate Index comprised 21 companies and the Datastream UK Real Estate Index, 30 companies. The Datastream Australian Real Estate Index is used as a proxy for the market index, against which the performance of the expert systems 'value' portfolios is compared. Market capitalisation (MV), dividend yield (DY), price-to-book-value (PTBV), price-earnings (PE), price-to-cashflow (PC) and total return (TR) data is collected for the two market indices (Australia and the UK). As for the individual stocks, the Index total return represents the cumulative points gain or loss due to changes in the share prices of stocks in the index and normal dividend payments. The total number of company observations over the full sample period is 1766 for Australian real estate stocks, and 2758 for UK real estate stocks.

For each company in the sample, the following data has been collected; closing price (P), market capitalisation (MV), dividend yield (DY), price-to-book-value (PTBV), priceearnings (PE) and price-to-cashflow (PC). Closing prices and the dividend yield for each company are used to calculate the total return index for each stock as follows:

\footnotetext{
${ }^{1}$ A Datastream calculated index, the 'Real Estate' series is based on the FTSE classification and includes the following sub-sectors: Real Estate Development, Property Agencies, and Real Estate Investment Trusts.
} 


$$
R I_{t}=R I_{t-1} \times \frac{P_{t}}{P_{t-1}} \times\left(1+\frac{D Y_{t}}{100} \times \frac{1}{12}\right)
$$

where $P_{t}$ and $D Y_{t}$ are the price and dividend yield at time $t$ respectively, and $R I_{t}$ is the total return index. This formulation for the total return is identical to that used by Datastream to estimate the Return Index, and adjusts the total return for the monthly frequency used in this study. ${ }^{2}$ Total return is then calculated as the log difference of the total return index:

$$
R_{t}=\log R I_{t}-\log R I_{t-1}
$$

As not all stocks traded for the full length of the test period (1997 - 2004), this avoids problems associated with survivorship bias that may influence the results (cf. Brown et al, 1992).

For the purposes of estimating the total return to an Australian investor from a position in the UK market, monthly closing prices for the Australian Dollar / British Pound (AUD/GBP) exchange rate have also been collected. The total return to an Australian investor from an investment in UK assets includes both a capital gain or loss component, and an exchange rate gain (loss) component.

\section{RESEARCH METHODOLOGY}

The current paper uses as its expert knowledge inference set the outcomes from the research of Haugen (1995), O'Shaughnessy (1998), and Eakins and Stansell (2003) to select a group of fundamental financial ratios that will be used to determine sets (portfolios) of 'value' securitised property assets. These fundamental variables form the inputs to a rule-based expert system that has preset constraints to isolate 'value' assets. 'Value' assets are commonly defined as those whose market value is lower than their intrinsic or liquidating value (O'Shaughnessy, 1998). The attraction of value assets from an investor's point of view is that the (lower) market value of the asset should rise to meet the (higher) intrinsic value. This being true, portfolios comprised of value assets should outperform portfolios comprised of all assets. Portfolio allocation to value stocks is sometimes referred to as a 'contrarian investment strategy'. A number of studies indicate that contrarian strategies can outperform a strategy of investing in 'growth'

\footnotetext{
${ }^{2}$ The Datastream model for total return is based on a daily frequency and uses 260, rather than 12, in the denominator. Ellis and Wilson (2005) use price and dollar dividend in their construction of the return index, which differs from the return index in this paper.
} 
stocks (cf. Fama and French, 1996, 1998; Haugen, 1995; Lakonishok et al, 1994; Levis and Liodakis, 2001).

In a comprehensive study of the comparative performance of US equities, O'Shaughnessy (1998) identifies a number of factors as being determinants of value. These include large stocks with low price/earnings ratios; low price/book ratios; low price/cashflow ratios; low price/sales ratios; high dividend yields. 'Large' stocks are defined by O'Shaughnessy as those with a higher than average market capitalization. Stocks with 'low' ('high') ratios are defined as those for which the relevant ratio is lower (higher) than the market average. For instance, a 'low P/E' ratio stock is one with a lower than market average $\mathrm{P} / \mathrm{E}$ ratio, and a 'high $\mathrm{P} / \mathrm{E}$ ' ratio stock is one with a higher than market average $\mathrm{P} / \mathrm{E}$ ratio. Given the lower volatility of large stocks relative to all stocks, value portfolios comprised of large stocks are shown by O'Shaughnessy to typically outperform the market index by a sizeable margin on a risk-adjusted basis. Using neural network techniques to predict value stocks using the ratios identified by O'Shaughnessy, Eakins and Stansell (2003) demonstrate the superior performance of the neural network value portfolio versus the S\&P 500 and Dow Jones Industrial Average. Following the work of Eakins and Stansell (2003), Ellis and Wilson (2005) recently investigated the performance of value portfolios comprised of Australian real estate stocks using a similar neural network methodology to identify individual value stocks ${ }^{3}$.

To go some way towards reducing the above mentioned deficiency in the literature on rule-based expert systems in property research, the current paper develops a rule-based expert system to construct portfolios of Australian and UK listed property stocks and compare the performance of these portfolios against the Datastream Australian Real Estate Index. The primary objective of research in this study is to examine the performance of expert system value portfolios comprised of property sector value stocks versus the set of all property sector stocks. The performance of each portfolio is compared first to the Australian market index, and second to mean statistics for 100 randomly diversified portfolios of Australian and UK listed property stocks. For portfolios comprised of UK listed property stocks, consideration is also given to the potential gain or loss from foreign exchange risk borne by Australian investors in the

\footnotetext{
${ }^{3}$ There is an important difference between a rule based expert system, as used here, and a neural network. A rule based expert system operates in a strictly linear fashion following the if....then sequence of rules that have been embedded in the system. This contrasts starkly with that of a neural network in that the neural network is provided with a set of input and output conditions from which it 'learns' behaviour patterns. The input/output relationship is determined by some embedded non-linear function, consequently the 'true' non-linear relationship between the variables is not apparent - owing to the presence of hidden layers. So, the expert system is pre-determined to produce a certain output so long as the set of rules are satisfied. On the other hand, a neural network 'learns' according to the set of input/output conditions that exist in the training phase. The set of if... then expert rules in this paper have been obtained from the literature and are equivalent to the input conditions.
} 
UK, and to the cost of hedging such risk and its impact on the profitability of foreign (UK) investments.

Rather than the CAPM, which has not been shown to accurately reflect investor sentiment towards risk (Eakins and Stansell, 2003), risk adjusted performance relative to the Australian market index is measured first by the Sharpe ratio (Sharpe, 1966), and second the Sortino ratio (Sortino and Forsey, 1996; Sortino et al, 1997) for adjusting returns on a downside risk basis.

The Sharpe ratio is the conventional approach to the measurement of risk in that it includes both upside and downside risk i.e. outperformance of the portfolio is treated exactly the same as underperformance. The Sharpe ratio is given as:

$$
\text { Sharpe ratio }=\frac{R_{p}-R_{f}}{\sigma_{r}}
$$

where $R_{f}$ is the risk free rate of return, $R_{p}$ is the return to the portfolio and $\sigma_{r}$ is the standard deviation of portfolio returns. The Sharpe ratio provides a measure of return per unit of risk with a ratio in excess of 1.0 being considered good. On the other hand the Sortino ratio is calculated as the difference between the portfolio return $R_{p}$ and the minimum acceptable return $M A R$, divided by the downside deviation $D D$ of the portfolio return versus the minimum acceptable return $D D_{M A R}$. Downside deviation is similar to the loss standard deviation with the exception that it $(D D)$ only includes portfolio returns below the MAR, rather than portfolio returns below the mean. The basis of the Sortino ratio is that investors are more concerned with the risk of loss (downside risk), than the risk of gains (upside risk). Standard deviation, as used by the Sharpe Ratio, considers both upside and downside risk. The calculation of the Sortino ratio is given as:

$$
\begin{aligned}
& \text { Sortino ratio }=\frac{R_{p}-R_{M A R}}{D D_{M A R}} \\
& D D_{M A R}=\sqrt{\frac{\sum_{i=1}^{N}\left(L_{i}\right)^{2}}{N}} \\
& L_{i}=\left(R_{i}-R_{M A R}\right) \quad \text { if }\left(R_{i}-R_{M A R}\right)<0 \\
& \text { or } \quad \text { if }\left(R_{i}-R_{M A R}\right)>0
\end{aligned}
$$


For consistency with the calculation of the Sharpe ratio, the Sortino ratio MAR is set equal to the mean monthly risk-free rate of $0.49 \%$, this being the mean of the monthly Australian 10-year Commonwealth Bond rate for the test period. ${ }^{4}$

Several systems are tested in this study, including both single-factor and multiple-factor systems. Following from Ellis and Wilson (2005), the initial set of input factors employed for both the Australian and UK markets comprises market capitalisation (MV), dividend yield (DY), price-to-book-value (PTBV), price-earnings (PE), and price-tocashflow (PC). Market average ratios (for comparison) are calculated annually as the average ratio for all stocks in the index each given year. Expert systems testing for UK listed property stocks also includes the effective rate of return (EffR), with the motivation being that Australian investors in the UK will gain from an appreciation of the foreign currency (GBP) net of any capital loss on the asset. To prevent look-ahead bias associated with making investment decisions based on data which is not yet known, portfolios constructed at time $t$ comprise stocks which are identified by the system as being value stocks at time $t-1$. Despite the fact that the AUD/GBP exchange rate is readily observable on a 24 -hour basis, information pertaining to other factors (eg. PTBV, PC) may not be readily known (Eakins and Stansell, 2003). Stock specific information pertaining to the first-order autocorrelation structure and mean excess percentage returns for each factor for the year prior is also included. The additional information is incorporated into the rule-based expert system to determine a priori the raw probability of a value stock at time $t-1$ being value at time $t$. While the full sample period comprises company and index data from 1996 - 2004 inclusive, the expert systems under consideration are tested over the period $1997-2004$.

\section{Single-factor systems testing}

Single-factor expert systems in this study incorporate information pertaining to a single input factor only. Individual systems are tested for each of the five input factors listed above for the Australian market, and six (including information pertaining to monthly changes in the AUD/GBP) for the UK market. The rule-set developed a binary classification system so that the output factor for the single-factor system is defined as either VALUE or NOT according to the value criteria that was previously established for each respective input. Repeating the process for each of the input factors yields a total of five single-factor value portfolios for the Australian market and six single-factor value portfolios for the UK market.

\footnotetext{
${ }^{4}$ Source, OECD Main Economic Indicators. Annual average equals 5.9\%
} 


\section{Multiple-factor systems testing}

As opposed to the single-factor systems which classify stocks as being VALUE or NOT on the basis of a single criteria, only the multiple-factor rule-set ranks stocks in terms of the degree of value when measured against all criteria simultaneously. Individual stocks are awarded a cumulative score out of 5 in each period (score out of 6 in the UK) based on how many of the individual value criteria are identified by the expert system as being satisfied. For a stock listed in the Datastream Australian Real Estate Index, a cumulative value score of 5 in any given month would indicate that the stock satisfied all of the relevant value criteria. A value score of 0 alternatively shows that the stock satisfied none of the criteria. A cumulative score of 6 for a stock listed in the Datastream UK Real Estate Index would likewise show that the stock satisfied all of the value criteria in the UK market.

Using the multiple-factor value criteria, 'multi-value' stocks are then defined as those with a cumulative value score $\geq 4$. The testing of multi-value stock portfolios in addition to value stock portfolios (based on a single-value criteria only) is to evaluate the potential value-added by imposing a stricter value criteria on stocks during each period. Given the inclusion of the effective rate of return (EffR) as a value input in the UK market, two multi-value stock portfolios are tested in the UK. The first, Multi 1 comprises information pertaining to market capitalisation (MV), dividend yield (DY), price-tobook-value (PTBV), price-earnings (PE), and price-to-cashflow (PC) only, while the second, Multi 2 comprises these five plus information pertaining to the effective rate of return (EffR). Excluding the effective rate of return from the first UK multi-value portfolio allows the performance of this to be directly compared to the equivalent Australian multi-value portfolio. Its inclusion in the second UK multi-value portfolio allows the contribution of expected exchange rate changes to be measured separately.

The binary classification in the multi-value context operates in much the same way as for the single-factor models: stocks scoring a cumulative value score $\geq 4$ are classified as VALUE, stocks with a cumulative score $<4$, NOT.

\section{RESULTS}

\section{Descriptive statistics}

Summary statistics pertaining to monthly returns for Datastream Australian Real Estate Index and the Datastream UK Real Estate Index are provided in Table 1. The Datastream Australian Real Estate Price Index started the sample period (January 1996) at 634.77 points and finished on February 2004 at 1109.1. The Datastream UK Real Estate Price Index started at 1780.04 points and finished at 2864.05. The mean return to the Australian market index is approximately $1.02 \%$, and for the UK market index is $0.77 \%$. The AUD/GBP started at 2.0882 AUD per 1 GBP and finished at 2.3952 implying 
Australian investors with a long position in GBP denominated assets would realize an exchange gain of about 0.3070 AUD per 1 GBP invested.

Table 1 : Descriptive Statistics of Australian and UK Real Estate Index Returns, and AUD/GBP Exchange Rate, 1/01/1996 - 1/02/2004

\begin{tabular}{lccc}
\hline & $\begin{array}{c}\text { Australia DS } \\
\text { Real Estate }\end{array}$ & $\begin{array}{c}\text { UK DS Real } \\
\text { Estate }\end{array}$ & AUD/GBP \\
\hline \hline Count & 98 & 98 & 98 \\
Mean & 0.0102 & 0.0077 & 0.0025 \\
Standard Deviation & 0.0355 & 0.0489 & 0.0340 \\
Excess Kurtosis & 0.3090 & 0.3644 & 0.0668 \\
Skewness & 0.1190 & -0.4406 & 0.2532 \\
Minimum & -0.0765 & -0.1195 & -0.0804 \\
Maximum & 0.1219 & 0.1340 & 0.0971 \\
Sum of $l n$ returns & 1.0043 & 0.7557 & 0.2010 \\
Value: start of period & 634.77 & 1780.04 & 2.0882 \\
$\quad$ end of period & 1109.1 & 2864.05 & 2.3952 \\
$\begin{array}{l}\text { Gain (loss) } \\
\text { Runs test }(p \text {-value) }\end{array}$ & 474.33 & 1084.01 & 0.3070 \\
$\begin{array}{l}\text { Ljung-Box Q }(1) \\
(p \text {-value) }\end{array}$ & 0.2160 & 0.4740 & 0.3100 \\
$\begin{array}{l}\text { Anderson-Darling } \\
(p \text {-value) }\end{array}$ & 0.0137 & 0.1351 & 0.2796 \\
$\begin{array}{l}\text { Ryan-Joiner } \\
(p \text {-value) }\end{array}$ & 0.9490 & 0.0410 & 0.5290 \\
\hline
\end{tabular}

To establish the degree of randomness in monthly returns for the Australian and UK indices and the AUD/GBP, a non-parametric runs test is conducted. This test accepts randomness for all three series at the $10 \%$ level. Each series is then tested for the presence of first-order autocorrelation, the significance of which is tested using the Ljung-Box Q statistic. The significant test result for the Australian market confirms negative autocorrelation in the index, suggesting a higher than expected probability of consecutive price changes in the opposite direction. The Anderson-Darling test for the normality of returns fails to reject the null hypothesis that Australian market index returns follow a Normal distribution, but rejects the Normal null for the UK market index. The Normal null is accepted for the GBP/AUD at the 10\% level. The Ryan-Joiner p-value similarly rejects the Normal null at the $10 \%$ level for the UK Market index and accepts the null for both of the Australian market index and the GBP/USD. 


\section{Expert system value portfolios}

The performance of each of the expert system value portfolios relative to the Australian market index is shown in a series of tables. Table 2 describes the performance of expert system value portfolios comprised of Australian real estate stocks, and Table 3 the performance of expert system value portfolios comprised of UK real estate stocks. Portfolios in both tables are compared to the Australian market index as proxied by the Datastream Australian Real Estate Index and to mean statistics for 100 randomly diversified portfolios drawn from the set of all Australian and UK listed property stocks.

Table 2: Performance of Australian Expert System Value Portfolios: 1997 - 2004

\begin{tabular}{lcccccccc}
\hline & MV & DY & PC & PE & PTBV & Multi & Market Random \\
\hline \hline $\begin{array}{l}\text { Mean } \\
\text { Monthly }\end{array}$ & & & & & & & & \\
Return & $0.64 \%$ & $0.37 \%$ & $0.22 \%$ & $0.39 \%$ & $0.37 \%$ & $0.36 \%$ & $0.93 \%$ & $0.44 \%$
\end{tabular}

Standard

$\begin{array}{lllllllll}\text { Deviation } & 0.0392 & 0.0286 & 0.0247 & 0.0268 & 0.0261 & 0.0285 & 0.0358 & 0.0284\end{array}$

Downside

$\begin{array}{lllllllll}\text { Deviation } & 0.0262 & 0.0211 & 0.0191 & 0.0200 & 0.0196 & 0.0204 & 0.0225 & 0.0207\end{array}$

Sharpe

Ratio

$0.0371-0.0413$

$-0.1103$

$-0.0040-0.0297$

0.0542

$0.1225-0.0191$

Sortino

Ratio

$0.0556-0.0562$

$-0.1423$

$-0.0055-0.0404$

0.0813

$\begin{array}{ll}0.1949 & -0.0247\end{array}$

Max

Monthly

Gain

$14.39 \%$

$8.91 \%$

$6.48 \%$

$7.80 \%$

$7.53 \% \quad 10.30 \%$

$12.19 \% \quad 8.23 \%$

Max

Monthly

Loss

$$
-9.93 \%-6.97 \%
$$

$-7.33 \%$

$-6.67 \% \quad-6.61 \% \quad-7.65 \% \quad-7.21 \%$

Cumulative

Mean

Return

$54.16 \% \quad 31.72 \%$

$18.65 \% \quad 33.41 \%$

$31.71 \% \quad 30.25 \% \quad 79.06 \% \quad 37.19 \%$

Compound

Return \begin{tabular}{llllllll}
$60.90 \%$ & $32.57 \%$ & $17.41 \%$ & $35.40 \%$ & $33.34 \%$ & $30.70 \%$ & $108.27 \%$ & $67.59 \%$ \\
\hline
\end{tabular} 
Nominal monthly mean returns for each of the expert system value portfolios in Table 2 are less than the mean return to the Australian market index $(0.930 \%)$. The highest mean return is for the market capitalisation portfolio $M V(0.640 \%)$ and the lowest is for the price-to-cashflow portfolio $(0.392 \%)$. An analysis of $\mathrm{z}$ scores and $\mathrm{p}$-values for the difference between mean returns to the market portfolios and the expert systems value portfolios reveals that the level of underperformance is not significant at the 0.10 level. Only the market value portfolio outperformed the bootstrap mean, though the difference is again insignificant at the 0.10 level. Compared to mean returns for each of the singlefactor portfolios, $p$-values for the difference between the multi-factor portfolio mean return and single-factor mean returns is likewise insignificant. ${ }^{5}$

Cumulative mean returns for all portfolios over the test period are lower than the cumulative mean market return (79.064\%) and the bootstrap mean cumulative return (37.188\%) except for the market capitalisation portfolio which returns $54.164 \%$ for the 86-months to February 2004. Cumulative mean returns in this study are calculated as the sum of monthly portfolio returns and do not include the effects of monthly compound interest. Compound returns - the percentage return to $\$ 1$ invested at the beginning of the test period and subsequently reinvested at each period's monthly rate of return - are also calculated. Consistent with the cumulative returns, none of the expert system value portfolios in Table 2 were able to outperform the market, nor the bootstrap mean on a compound returns basis.

Risk-adjusted returns in this study are calculated using the Sharpe ratio and the Sortino ratio. In contrast with findings already discussed, the difference between expert system value portfolio Sharpe ratios and Sortino ratios versus the market portfolio or the bootstrap mean Sharpe and Sortino ratios is statistically significant for all portfolios at the $10 \%$ level.

Results pertaining to the performance of UK expert system value portfolios are presented in Table 3. Relative to the performance of the Australian market index, results in Table 3 are for the effective rate of return to an Australian investor from a position in UK (GBP denominated) assets. Calculated as

$$
R_{A U D}=\left[\left(1+R_{G B P}\right) *\left(1+\Delta S_{A U D / G B P}\right)\right]-1
$$

where $R_{A U D}$ is the AUD denominated total return, $R_{G B P}$ is the GBP denominated capital return, and $\triangle S_{A U D / G B P}$ is the change in the spot Australian Dollar/British Pound exchange rate, returns in Table 3 include both a capital gain and exchange gain component.

\footnotetext{
${ }^{5} \mathrm{z}$ scores and p-values for the difference between the Multi-Value portfolio mean return and single-factor mean returns, not reported in this study, are available from the authors by request.
} 
Table 3: Performance of UK Expert System Value Portfolios: 1997 - 2004

\begin{tabular}{|c|c|c|c|c|c|}
\hline & MV & DY & $P C$ & $P E$ & PTBV \\
\hline Mean Monthly Return & $0.50 \%$ & $0.52 \%$ & $0.80 \%$ & $0.81 \%$ & $0.44 \%$ \\
\hline Standard Deviation & 0.0515 & 0.0442 & 0.0430 & 0.0419 & 0.0434 \\
\hline Downside Deviation & 0.0366 & 0.0319 & 0.0299 & 0.0289 & 0.0328 \\
\hline Sharpe Ratio & -0.0579 & 0.1118 & 0.1614 & 0.1309 & 0.2269 \\
\hline Sortino Ratio & -0.0760 & 0.1658 & 0.2520 & 0.2002 & 0.3874 \\
\hline Max Monthly Gain & $12.78 \%$ & $11.23 \%$ & $10.01 \%$ & $10.05 \%$ & $10.04 \%$ \\
\hline Max Monthly Loss & $-11.46 \%$ & $-13.54 \%$ & $-10.07 \%$ & $-10.75 \%$ & $-11.60 \%$ \\
\hline Cumulative Mean Return & $42.84 \%$ & $44.52 \%$ & $68.27 \%$ & $68.43 \%$ & $37.39 \%$ \\
\hline \multirow[t]{2}{*}{ Compound Return } & $37.09 \%$ & $43.45 \%$ & $82.54 \%$ & $83.57 \%$ & $33.93 \%$ \\
\hline & Multi1 & $E f f R$ & Multi2 & Market & Random \\
\hline Mean Monthly Return & $0.30 \%$ & $2.74 \%$ & $1.43 \%$ & $0.93 \%$ & $0.87 \%$ \\
\hline Standard Deviation & 0.0455 & 0.0373 & 0.0424 & 0.0358 & 0.0454 \\
\hline Downside Deviation & 0.0353 & 0.0222 & 0.0265 & 0.0225 & 0.0313 \\
\hline Sharpe Ratio & -0.0411 & 0.6030 & 0.2213 & 0.1225 & 0.0844 \\
\hline Sortino Ratio & -0.0530 & 1.0113 & 0.3539 & 0.1949 & 0.1243 \\
\hline Max Monthly Gain & $9.63 \%$ & $12.26 \%$ & $9.54 \%$ & $12.19 \%$ & $11.13 \%$ \\
\hline Max Monthly Loss & $-17.01 \%$ & $-8.71 \%$ & $-11.01 \%$ & $-7.65 \%$ & $-11.96 \%$ \\
\hline Cumulative Mean Return & $25.89 \%$ & $248.96 \%$ & $122.76 \%$ & $79.06 \%$ & $74.22 \%$ \\
\hline Compound Return & $18.38 \%$ & $772.2 \%$ & $196.74 \%$ & $108.27 \%$ & $105.20 \%$ \\
\hline
\end{tabular}

Inclusive of a mean monthly exchange rate gain of approximately $0.186 \%$, mean returns to all single factor portfolios, except the effective rate of return value portfolio EffR, underperform both the Australian market index return and the bootstrap mean return. The multi-factor model Multi 2, which incorporates information pertaining to exchange rate 
changes, also outperform both the market and the bootstrap mean. The effective rate of return value portfolio earns the highest mean monthly return $(2.742 \%)$ and the multifactor portfolio Multi 1 , the lowest $(0.186 \%)$. With the exception of the effective rate of return value portfolio, expert system value portfolio mean monthly returns are not significantly different to either the mean monthly market return or the bootstrap mean return. Cumulative mean and compound returns to the above listed portfolios also exceed the market portfolio and bootstrap mean returns, though the statistical significance of the difference in cumulative mean returns cannot be ascertained. Sharpe and Sortino ratios for all of the portfolios in Table 3, except the price-earnings value portfolio PE, are likewise significantly different to the market portfolio Sharpe and Sortino ratios. Of these, only the effective rate of return value portfolio yields Sharpe and Sortino ratios which are statistically greater than the corresponding market ratios.

\section{Hedging foreign exchange exposure}

For Australian investors with open positions in foreign currency denominated assets, two questions arise; namely: what is the contribution of exchange gains or losses to overall portfolio performance; and whether the underlying exchange rate risk should be actively managed. Appreciation of the foreign currency will increase the domestic currency value of foreign currency denominated assets, and depreciation will decrease the value of foreign currency denominated assets. Results presented in Table 3 comprise both a capital gain (loss) component and an exchange rate gain (loss) component, i.e. the effective rate of return to an Australian investor. To consider the impact of currency variability on portfolio returns in Table 3 , Table 4 provides comparative returns for the cases where (i) the AUD/GBP exchange rate is fixed, and (ii) the exchange risk is fully hedged. 
Table 4: AUD/GBP Exchange Rate Variability and the Performance of UK Expert System Value Portfolio: 1997 - 2004

\begin{tabular}{|c|c|c|c|c|c|c|c|c|}
\hline & $M V$ & $D Y$ & $P C$ & $P E$ & PTBV & Multi1 & EffR & Multi2 \\
\hline & \multicolumn{8}{|c|}{ Fixed Exchange Rate } \\
\hline Mean Monthly Return & $0.39 \%$ & $0.41 \%$ & $0.69 \%$ & $0.69 \%$ & $0.33 \%$ & $0.18 \%$ & - & - \\
\hline Standard Deviation & 0.0540 & 0.0469 & 0.0460 & 0.0449 & 0.0469 & 0.0464 & - & - \\
\hline Downside Deviation & 0.0403 & 0.0370 & 0.0353 & 0.0343 & 0.0384 & 0.0381 & - & - \\
\hline Sharpe Ratio & -0.0182 & -0.0170 & 0.0436 & 0.0450 & -0.0341 & -0.0663 & - & - \\
\hline Sortino Ratio & -0.0244 & -0.0215 & 0.0569 & 0.0589 & -0.0415 & -0.0806 & - & - \\
\hline Max Monthly Gain & $15.92 \%$ & $10.22 \%$ & $11.32 \%$ & $10.10 \%$ & $12.68 \%$ & $12.39 \%$ & - & - \\
\hline Max Monthly Loss & $-12.51 \%$ & $-15.67 \%$ & $-11.71 \%$ & $-12.17 \%$ & $-13.77 \%$ & $-19.05 \%$ & - & - \\
\hline Cumulative Mean Return & $33.42 \%$ & $35.04 \%$ & $58.86 \%$ & $58.98 \%$ & $28.22 \%$ & $15.69 \%$ & - & - \\
\hline \multirow[t]{2}{*}{ Compound Return } & $23.24 \%$ & $28.97 \%$ & $64.10 \%$ & $65.04 \%$ & $20.42 \%$ & $6.42 \%$ & - & - \\
\hline & \multicolumn{8}{|c|}{ Costless Hedging } \\
\hline Mean Monthly Return & $2.63 \%=$ & $1.71 \%$ & $2.93 \%=$ & $2.00 \%=$ & $2.56 \%=$ & $2.41 \%=$ & $5.73 \%=$ & $3.64 \%=$ \\
\hline Standard Deviation & 0.0546 & 0.0460 & 0.0450 & 0.0437 & 0.0462 & 0.0466 & 0.0404 & 0.0441 \\
\hline Downside Deviation & 0.0287 & 0.0237 & 0.0220 & 0.0210 & 0.0255 & 0.0225 & 0.0093 & 0.0191 \\
\hline Sharpe Ratio & 0.3913 & 0.4669 & 0.5418 & 0.5579 & 0.4475 & 0.4124 & 1.2966 & 0.7139 \\
\hline Sortino Ratio & 0.7456 & 0.9083 & 1.1095 & 1.1612 & 0.8123 & 0.7068 & 5.6326 & 1.6483 \\
\hline Max Monthly Gain & $14.51 \%$ & $12.31 \%$ & $13.25 \%$ & $13.44 \%$ & $12.73 \%$ & $11.94 \%$ & $16.64 \%$ & $13.51 \%$ \\
\hline Max Monthly Loss & $-11.46 \%$ & $-12.67 \%$ & $-10.07 \%$ & $-10.75 \%$ & $-11.39 \%$ & $-16.17 \%$ & $-8.93 \%$ & $-11.01 \%$ \\
\hline Cumulative Mean Return & $223.43 \%$ & $224.52 \%$ & $248.81 \%$ & $248.91 \%$ & $217.61 \%$ & $205.25 \%$ & $436.38 \%$ & $306.77 \%$ \\
\hline Compound Return & $703.51 \%$ & $740.83 \%$ & $969.91 \%$ & $975.98 \%$ & $685.120 \%$ & $593.84 \%$ & $2017.4 \%$ & $1176.2 \%$ \\
\hline
\end{tabular}

= significantly different to the Datastream Australian Real Estate Index at the 0.10 level

$==$ significantly different to the Datastream Australian Real Estate Index at the 0.05 level 
While portfolio mean returns net of GBP appreciation may be inferred from Table 3 via subtraction of the mean monthly forex gain from the mean monthly return, Table 4 provides exact mean returns for the UK value portfolios exclusive of exchange rate gains or losses. Assuming that the AUD/GBP exchange rate is at par for the entire test period, the change in the AUD/GBP in Equation (3) is therefore zero. In terms of cumulative returns, appreciation of the GBP over the test period can be seen to add from $9.17 \%$ (price-to-book-value) to $10.20 \%$ (Multi 1). Compound returns are approximately $11.96 \%$ (Multi 1) to $18.53 \%$ (price-earnings) higher. Despite the fact that mean returns in Table 3 are not statistically different to those given a fixed exchange rate in Table 4, the difference in compound returns illustrates the value of foreign currency appreciation to Australian investors.

Expert systems value portfolios purchased at time $\mathrm{t}$ use all available information up to the previous period, $t-1$. By avoiding look-ahead bias, the investor now bears the risk that changes in the values of expert system input variables (used to designate a stock as being VALUE or NOT) between $t$ and $t-1$ will result in capital and/or exchange losses. To manage exchange rate risk between time $t-I$ and $t$, the hedge in Table 4 is constructed along the following lines: at time $t-1$, the investor purchases an AUD/GBP foreign exchange option with an exercise value equal to the then current spot exchange rate. The option maturity is the next period, time $t$. If the GBP depreciates between time $t-1$, and $t$, the option is exercised and the portfolio effective rate of return is calculated on the change in the AUD/GBP to time $t-1$. Else if the GBP appreciates between time $t-1$ and $t$, then the option expires worthless and the portfolio effective rate of return is calculated on the change in the AUD/GBP to time $t$. The hedge strategy follows from that employed by Ziobrowski and Ziobrowski (1993) into the benefits to US investors of hedging longterm positions in British Pound and Japanese Yen denominated real estate stocks with currency options. Despite the short-term gains from managing exchange rate risk with currency options, the authors concluded that 'as a long-term strategy, the currency option offers no real protection against foreign asset devaluation caused by currency devaluation' (Ziobrowski and Ziobrowski, 1993).

Under the initial assumption that the above described hedge is costless, i.e. the option premium is zero, results for the Costless Hedging expert systems value portfolios in Table 4 show a significant degree of outperformance relative to the Datastream Australian Real Estate Index with cumulative returns as high as $336.38 \%$, and compound returns as high as $2017.4 \%$ for the effective rate of return portfolio. Furthermore, mean returns given costless hedging in Table 4 are also significantly greater than their respective unhedged values in Table 3 at the 0.10 level, and returns to all except the dividend yield and price-earnings value portfolios are significantly greater at the 0.01 level. Relative to mean monthly returns presented in Table 3 , the additional mean monthly portfolio return of approximately $1.19 \%$ to $2.99 \%$ implies a potentially substantial benefit from hedging foreign exchange risk. 
Under the assumption of costless hedging with currency options, fully hedged returns in Table 4 have already been shown to be significantly greater than their unhedged values. To determine the impact of the cost of the option premium on portfolio returns, Table 5 provides the return to an initial $\$ 1$ investment, reinvested each period over the full sample for Australian expert systems portfolios, and for each of the UK expert system value portfolios given the cases where (i) exchange rate risk is unhedged, (ii) exchange risk is costlessly hedged (Hedged Gross), (iii) the real cost of the option premium is deducted from each period's reinvested value (Hedged Net) ${ }^{6}$. Real option premiums each period are calculated using the Garman and Kohlhagen (1983) modified Black-Scholes model for valuing foreign currency options:

$$
\begin{aligned}
& C=S e^{-r_{f} t} N\left(d_{1}\right)-X e^{-r t} N\left(d_{2}\right) \\
d_{1}= & \frac{\ln \left(\frac{S}{X}\right)+\left(r-r_{f}+\frac{1}{2} \sigma^{2}\right) t}{\sigma \sqrt{t}} \\
d_{2}= & d_{1}-\sigma \sqrt{t}
\end{aligned}
$$

where $C$ is the call option premium, $S=X$ are the spot AUD/GBP exchange rate at time $t-1$ and option exercise respectively, $r$ is the mean of the monthly Australian 10-year Commonwealth Bond rate, $r_{f}$ is the mean of the monthly UK 10-year Commonwealth Bond rate, and $\sigma$ is the annualized standard deviation of AUD/GBP monthly returns from January 1990 to December 1996. The average call option premium over the test period is 0.0419AUD and the total premium paid is 3.6009AUD.

${ }^{6}$ The UK - Hedged Net beginning of period value of \$0.96 is calculated as the \$1 initial investment less the initial option premium. 
Table 5: Returns from \$1Invested in Expert System Value Portfolios: 1997- 2004

\begin{tabular}{|c|c|c|c|c|c|c|c|c|c|c|c|c|c|c|c|c|}
\hline \multirow[b]{3}{*}{ Beginning-of-period value } & \multicolumn{2}{|c|}{$M V$} & \multicolumn{2}{|r|}{$D Y$} & \multicolumn{2}{|r|}{$P C$} & \multicolumn{2}{|r|}{$P E$} & \multicolumn{2}{|c|}{ PTBV } & \multicolumn{2}{|c|}{ Multi 1} & \multicolumn{2}{|r|}{ EffR } & \multicolumn{2}{|c|}{ Multi2 } \\
\hline & \multicolumn{16}{|c|}{ Australia } \\
\hline & $\$$ & 1.00 & $\$$ & 1.00 & $\$$ & 1.00 & $\$$ & 1.00 & $\$$ & 1.00 & $\$$ & 1.00 & & - & & - \\
\hline \multirow[t]{2}{*}{ End-of-period value } & $\$$ & 1.61 & $\$$ & 1.33 & $\$$ & 1.17 & $\$$ & 1.35 & $\$$ & 1.33 & $\$$ & 1.31 & & - & & - \\
\hline & \multicolumn{16}{|c|}{ UK Unhedged } \\
\hline Beginning-of-period value & $\$$ & 1.00 & $\$$ & 1.00 & $\$$ & 1.00 & $\$$ & 1.00 & $\$$ & 1.00 & $\$$ & 1.00 & $\$$ & 1.00 & $\$$ & 1.00 \\
\hline End-of-period value & $\$$ & 1.37 & $\$$ & 1.43 & $\$$ & 1.83 & $\$$ & 1.84 & $\$$ & 1.34 & $\$$ & 1.06 & $\$$ & 9.43 & $\$$ & 2.65 \\
\hline \multirow{4}{*}{ Beginning-of-period value } & \multicolumn{16}{|c|}{ UK Hedged Gross } \\
\hline & $\$$ & 1.00 & $\$$ & 1.00 & $\$$ & 1.00 & $\$$ & 1.00 & $\$$ & 1.00 & $\$$ & 1.00 & $\$$ & 1.00 & $\$$ & 1.00 \\
\hline & $\$$ & 8.04 & $\$$ & 8.41 & $\$$ & 10.70 & $\$$ & 10.76 & $\$$ & 7.58 & $\$$ & 6.94 & $\$$ & 21.80 & $\$$ & 13.46 \\
\hline & \multicolumn{16}{|c|}{ UK - Hedged Net } \\
\hline Beginning-of-period value & $\$$ & 0.96 & $\$$ & 0.96 & $\$$ & 0.96 & $\$$ & 0.96 & $\$$ & 0.96 & $\$$ & 0.96 & $\$$ & 0.96 & $\$$ & 0.96 \\
\hline End-of-period value & $-\$$ & 2.06 & $-\$$ & 2.59 & $-\$$ & 2.50 & $-\$$ & 2.51 & $-\$$ & 2.50 & $-\$$ & 3.16 & $\$$ & 0.87 & $-\$$ & 1.25 \\
\hline $\begin{array}{r}\text { Unhedged Req'd Monthly } \\
\text { Return }^{1}\end{array}$ & & $42 \%$ & & $43 \%$ & & $47 \%$ & & $.47 \%$ & & $42 \%$ & & $38 \%$ & & $.06 \%$ & & $.56 \%$ \\
\hline $\begin{array}{r}\text { Hedged Gross Req'd Monthly } \\
\text { Return }^{2}\end{array}$ & & $97 \%$ & & $00 \%$ & & $13 \%$ & & $.13 \%$ & & $94 \%$ & & $90 \%$ & & $.58 \%$ & & $.26 \%$ \\
\hline $\begin{array}{r}\text { Breakeven Req'd Monthly } \\
\text { Return }^{3}\end{array}$ & & $38 \%$ & & & & & & & & & & & & & & \\
\hline
\end{tabular}

\footnotetext{
${ }^{1}$ Average monthly required rate of return for which the Hedged Net end-of-period value equals the Unhedged end-of-period value

${ }^{2}$ Average monthly required rate of return for which the Hedged Net end-of-period value equals the Hedged Gross end-of-period value

${ }^{3}$ Average monthly required rate of return for which the Hedged Net end-of-period value equals $\$ 1.00$
} 
Consistent with compound returns in Table 2, returns to $\$ 1$ invested for all of the Australian expert system portfolios are less than would be earned by investment in the general property market. For UK expert system portfolios, end-of-period values for the hedged net portfolios are all lower than their respective unhedged and hedged gross endof-period values. Except for the effective rate of return portfolio, end-of-period UK hedged net values are negative. As illustrated by Figure 1, this result can be seen to be due to the cumulative impact of the premium on the future value of reinvested returns.

Figure 1: Mean of Compound Percentage Returns for UK Expert System Value Portfolios: 1997 - 2004

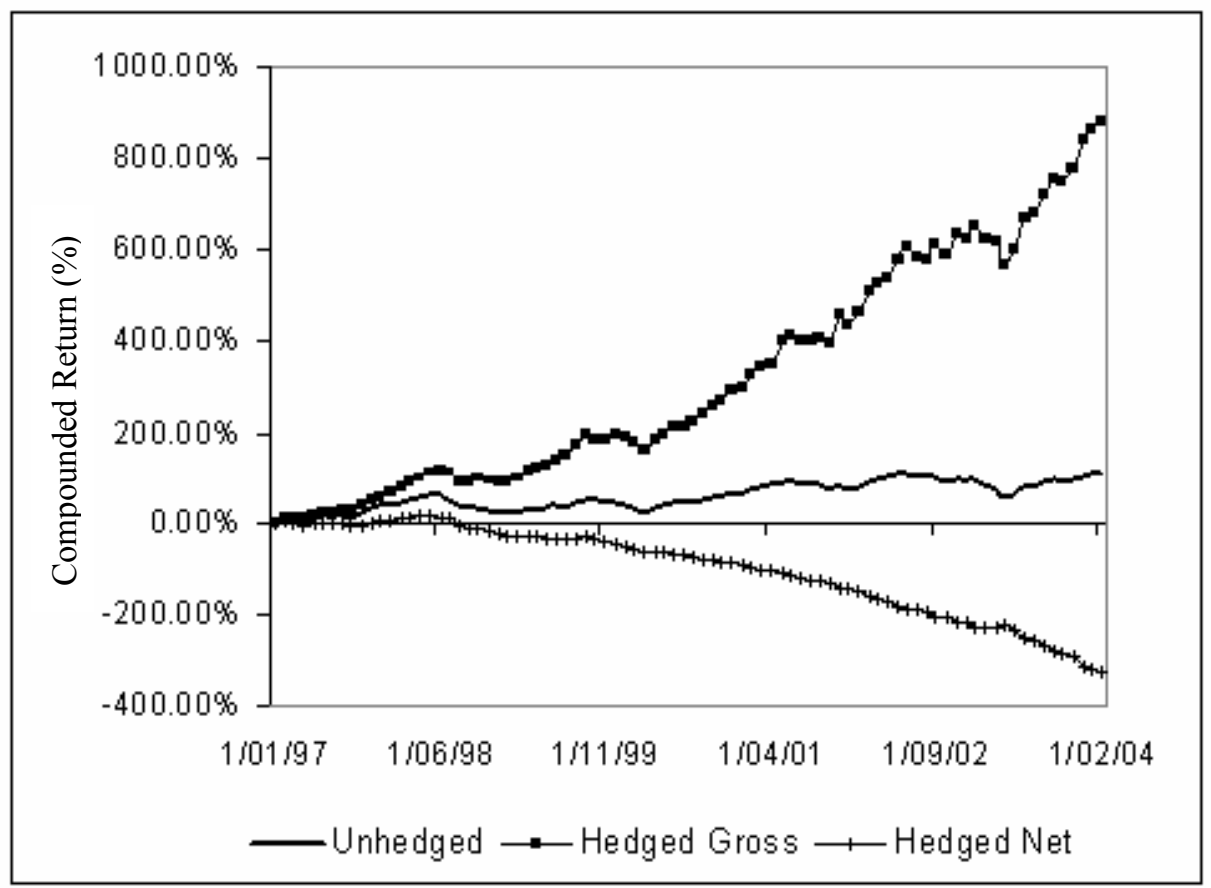

Despite the fact that UK hedged gross end-of-period values minus the nominal total premium exceeds the UK unhedged end-of-period values for all portfolios and the Australian market index end-of-period value, the subtraction of a premium each period reduces the value reinvested in the next period. This effect is cumulative over time resulting in much lower future values (compound returns) for the portfolios. Based on the average monthly call option premium of 0.0419AUD, estimation of the average monthly required rate of return in Table 5 shows that Australian investors would have to earn 
approximately $4.375 \%$ compounded monthly for the end-of-period UK hedged net portfolio value to equal the initial $\$ 1$ invested. This result is consistent with the earlier findings of Ziobrowski and Ziobrowski (1993) for US investors and confirms the incapacity of long-term hedged positions to return a yield in excess of the compound value of the option premium. The result does not preclude the viability of a short-term hedge strategy where, for instance a derivatives position is taken only when there is a forecast likelihood of foreign currency depreciation. The determination of a short-term hedge strategy is not attempted in the current study as the analysis of the AUD/GBP (refer Table 1) suggests the exchange rate cannot be accurately forecast.

\section{CONCLUSIONS}

There are a number of conclusions to flow from this study. First, the use of a rule-based expert system is capable of beating the general property market and randomly selected portfolios in select cases, although the outperformance is not statistically significant. This is in contrast to the outcomes from Ellis and Wilson (2005) who use a neural network system to develop portfolios that consistently outperformed the market. A possible explanation for this may be due to the fact that a neural network system is capable of picking up non-linear relationships that are unable to be identified by the rule-based system. The crucial finding in the paper is there appears to be no long term benefit to the Australian investor through hedging exposure to fluctuations in the AUD/GBP exchange rate, which is in broad agreement with the findings of Ziobrowski and Ziobrowski (1993) in relation to hedging US real estate. Further to Ziobrowski and Ziobrowski, we show this result is not due to the total cost of the premium, but rather is due to the continuous impact of the premium on compounded returns.

\section{REFERENCES}

Borst, R.A. 1991. Artificial Neural Networks: The Next Modeling/Calibration Technlogy for the Assessment Community? Property Tax Journal, 10(1), 69-94.

Brooks, C. and Tsolacos, S. 2003. International Evidence on the Predictability of Returns to Securitised Real Estate Assets: Econometric Models vs Neural Networks. Journal of Property Research, 20(2), 133-156.

Brown, S.J., Goetzmann, W., Ibbotson, R.G. and Ross, S.A. 1992. Survivorship Bias in Performance Studies. Review of Financial Studies, 5(4), 553-580.

Do, A.Q. and Grudnitski, G. 1992. A Neural Network Approach to Residential Property Appraisal. The Real Estate Appraiser, December, 38-45. 
Eakins, S.G. and Stansell, S.R. 2003. Can Value-based Stock Selection Criteria Yield Superior Risk-adjusted Returns: An Application of Neural Networks. International Review of Financial Analysis, 12, 83-97.

Ellis, C. and Wilson, P. 2005. Can a Neural Network Property Portfolio Selection Process Outperform the Property Market? Journal of Real Estate Portfolio Management, 11(2), 105-121.

Ellis Johnson, L., Redman, A.L., and Tanner, J.R. 1997. Utilization and Applications of Business Computing Systems in Corporate Real Estate. Journal of Real Estate Research, 13(2), 211-230.

Fama, E.F. and French, K.R. 1996. Size and Book-to-Market Factors in Earnings Returns. Journal of Finance, 51(1), 131-155.

Fama, E.F and French, K.R. 1998. Value versus Growth: The International Evidence. Journal of Finance, 53(6), 1975-1999.

Garman, M.B. and Kohlhagen, S.W. 1983. Foreign Currency Option Values. Journal of International Money and Finance, 2, 231-237.

Harmon, P. King, D. 1985. Artificial Intelligence in Business - Expert Systems. John Wiley and Sons: New York.

Haugen, R.A. 1995. The New Finance: The Case Against Efficient Markets. PrenticeHall: New Jersey.

Lakonishok, J., Shleifer, A. and Vishny, R. 1994. Contrarian Investment, Extrapolation and Risk. Journal of Finance, 49(5), 1541-1578.

Levis, M. and Liodakis, M. 2001. Contrarian Strategies and Investor Expectations. Financial Analysts Journal, 57(2), 43-56.

Liao, S. 2005. Expert System Methodologies and Applications - A Decade Review from 1995 to 2004. Expert Systems with Applications, 28, 93-103.

McGreal, S., Adair, A., McBurney, D., and Patterson, D. 1988. Neural Networks: The Prediction of Residential Values. Journal of Property Valuation and Investment, 16(1), 57-67.

Nguyen, N. and Cripps, A. 2001. Predicting Housing Value: A Comparison of Multiple Regression Analysis and Artificial Neural Networks. Journal of Real Estate Research, 22(3), 313-336. 
O’Shaughnessy, J.P. 1998. What Works on Wall Street. Revised Edition. McGraw-Hill: New York.

Sharpe, W.F. 1966. Mutual Fund Performance. Journal of Business, January, 119-138.

Sortino, F.A. and Forsey, H.J. 1996. On the Use and Misuse of Downside Risk. Journal of Portfolio Management, 22(2), 35-42.

Sortino, F.A., Miller, G.A., and Messina, J.M. 1997. Short-Term Risk-Adjusted Performance: A Style-Based Analysis. Journal of Investing, 6(2), 19-28.

Tay, D.P.H. and Ho, D.K.K. 1992. Artificial Intelligence and the Mass Appraisal of Residential Apartment. Journal of Property Valuation \& Investment, 10, 525-540.

Wilson, I.D., Paris, S.D., Ware, J.A., and Jenkins, D.H. 2002. Residential Property Time Series Forecasting with Neural Networks. Journal of Knowledge-Based Systems, 15, 335-341.

Wilson, P.J. and Zurbruegg, R. 2004. Contagion or Interdependence? Evidence from Comovements in Asian Securitised Real Estate Markets During the 1997 Crisis. Journal of Property Investment and Finance, 22(5), 401-413.

Wilson, P.J. and Zurbruegg, R. 2003. International Diversification of Real Estate Assets - Is it Worth It? Evidence from the Literature. Journal of Real Estate Literature, 11(3), 259-278.

Wilson, P.J. 1987. Expert Systems in Business, Vols. 1 and 2. MTE: Sydney.

Wong, B.K. and Monaco, J.A. 1995a. A Bibliography of Expert System Applications in Business (1984-1992), European Journal of Operational Research, 85, 416-432.

Wong, B.K. and Monaco, J.A. 1995b. Expert System Applications in Business: A Review and Analysis of the Literature (1977 - 1993). Information Management, 29, 141152.

Worzala, E., Lenk, M. and Silva, A. 1995. An Exploration of Neural Networks and its Application to Real Estate Valuation. Journal of Real Estate Research, 10(2), 185-201. Ziobrowski, A.J. and Ziobrowski, B.J. 1993. Hedging Foreign Investments in U.S. Real Estate with Currency Options. Journal of Real Estate Research, 8(1), 27-54. 